\title{
A Model of Participatory Academic Affairs Management based on Buddhadhamma of Phrapariyattidhamma Schools, General Education Division
}

\author{
PhramahaWasuthep $\bar{N}$ anamedhi (Namphu) ${ }^{1}$, SuddhipongSrivichai ${ }^{2}$, \\ PhramahaYannawatThitavaddhano $^{3}$, PhrakhruOpatnontakitti (Sakda Obhāso) ${ }^{4}$ \\ 1,2,3,4 Faculty of Education, Mahachulalongkornrajavidyalaya University \\ ${ }^{1}$ vi11.5811405023@gmail.com, ${ }^{2}$ suddhipong.sriv@mcu.ac.th, ${ }^{3}$ yannawat.bud@mcu.ac.th, ${ }^{4}$ opatnontakitti@mcu.ac.th
}

\begin{abstract}
The purposes of this research article were 1) to study the condition of participatory academic management, 2) to develop a model and to propose a participatory academic management model according to the Buddhist principles of Phrapariyattidhamma School, General Education Division. Mixed methods research was designed. There were 3 research steps: Step 1: Study the state of academic administration with participation. Use the sample questionnaire with 335 teachers. The data was analyzed by statistics, namely percentage, mean and standard deviation. Step 2 Develop the model by interviewing 14 key informants, and step 3, propose a participatory academic management model by collecting with a focus group discussion of 9 experts. The study found that 1) Academic management with participation in overall was at a high level in all 5 areas: the development of the quality assurance system within educational institutions, academic planning educational supervision, Teaching and learning management, and evaluation of learning outcomes in educational institutions, and research to improve the quality of education in educational institutions. 2) Model development, it is the introduction of Buddhist principles, namely, Sappurisatham VII, Sutta III, Four Noble Truths, Brahmavihara Dhammas IV and Iddhipada Dhamma, to integrate with the 5 aspects of participatory academic management. 3) A participatory academic work management model according to Buddhist principles of Phrapariyattidhamma School, general education division consisted of 1) principles, 2) objectives, 3) administrative processes, 4) evaluation. It is appropriate to apply for the participatory academic management of Phrapariyattidhamma School, General Education Division. Body of knowledge from this research can be summarized as ADEBE MODEL.
\end{abstract}

Keywords

Model, Participatory Academic Affairs Management, Buddhadhamma, Phrapariyattidhamma Schools

Article Received: 10 August 2020, Revised: 25 October 2020, Accepted: 18 November 2020

\section{Introduction}

The provision of ecclesiastical education is an option where a certain group of youth is interested and parents are encouraged to make this choice, sothat children can study in the temple which the study of Dhamma Department of General Education. It is a form of study of the Sanghawhich is an education place that is free from immorality and drugs. This type of education management nets hope to provide education for the youth of the nation who are under study age but lack the educational opportunity to be thoroughly educated. In which the temple will organize the address, food, cloth, tri-robe for the students. Most of the students will stay in the temple and in a situation where there are still a large number of children and young people who are still missing opportunities or disadvantaged in receiving educational services [1].

Educational management of Phrapariyattidhamma School Department of General Education has conducted teaching and learning for monks and novices only at the secondary level which is divided into 2 levels or is lower secondary education and high school. It is classified as a formal schoolas well as a typical public and private school model [2].The identity of Phrapariyattidhamma School of the general education department is the school to arrange for monks and novices to study additional subjects, namely Pali and Buddhism. According to the study curriculum Department of General Education and study the educational curriculum of the Sangha Department Pali as a basis for the study of Buddhism in the Scriptures and can be used as a missionary tool which is an important function of monks and novices as the heir of the successor of Buddhism as well. Therefore, it is considered that Phrapariyattidhamma School Department of General Educationproviding teaching and learning according to the core curriculum of basic education, B.E.2551, or the study of Dhamma, Dhamma and Pali department as well by organizing teaching and learning according to the Dharma and Pali curriculum in accordance with Sangha policy[3]. Management of Dhamma Studies Department of General Education overall, they faced problems in school education management and does not meet the standard. Therefore, there are many problems such as school administrators lack of knowledge and understanding and skills in the management of the system, lack of work plan. There are no strategies, goals and principles. Teachers have qualifications that do not match the subject matter taught and lack the knowledge and expertise in teaching and learning, curriculum development material production, developing into a school of learning, human resource development, overall internal quality assessment evaluation. There were differences in educational quality in terms of fundamentals of administrators, teachers, learners and quality of factors both internal and external environment School administration process Along with changing social, economic, school groups, the quality of education is even more different, each school is not up to the standard by the office for 
accreditation and quality assessment that has been established.

Therefore, administrators are of great importance to the academic administration that improves the quality of the school for efficiency and effectiveness. Management performance is an indicator of management success. The fact that administrators have an understanding of the role and function of educational administration will facilitate the successful management of education [5]. Method plan determination and steps in operating systematically because if the school administration system is not good, it will affect other areas of work in school. A good manager must choose a method that is appropriate and effective in order to accomplish its intended objectives[6].

By applying the Buddhist principles of administration as an attempt to apply the principles of Buddhism to modern subjects, Buddhism is an abstract higher than modern knowledge. It is therefore able to control both science and social science entirely. Then, the organization is stable and we can't stop there. It needs to be changed over time, called organizational development and can do both mundane and moral. For secular development, there are several possible approaches such as reengineering, human resource development or knowledge management, but for the development of a fair organization (Buddhist organization development) is the use of principles as a tool for organizational development. The variables that will be developed are the main components of the organization. When secular development is combined with natural development naturally makes that organization. A peace organization is a learning organization that have the ability to manage themselves and maintain the balance of the environment and is an organization with a spirit or community consciousness [7].

Therefore, the management of the Buddhist principles as a directive in the administration of all aspects is a harmonization. The concept of social ethics fits into function [8] shows that academic management problems are very important to the efficiency and effectiveness of the school. In addition, the academic administration of the educational institutes must rely on the administration of the school administrators as a priority. Department of General Education by adopting the principles of Buddhism that administrators can integrate into solving problems in academic administration within schools especially the Buddhist principles which are consistent with the principles of academic administration and the principles are suitable for academic administration.From the background and importance of the problem, the researcher was interested in conducting research on a participatory academic management model according to the Buddhist principles of Phrapariyattidhamma School Department of General Education. This will benefit the administrators, teachers, educational institutes and agencies related to educational institutes to be able to apply the principles of Buddhism in the educational establishment.

\section{Research Objectives}

The objectives of this research article were 1) to study the condition of participatory academic management, and 2) to develop a model and to propose a participatory academic management model according to the Buddhist principles of Phrapariyattidhamma School, General Education Division.

\section{Research Methods}

Mixed methods research was designed and there were 3 research steps as follows:

Step 1: Study the condition of academic administration with participation of Phrapariyattidhamma School, Department of General Education by studying documents on academic management with participation in order to create questionnaires. Data were collected from the population used in this research, namely 407 teachers in the Phra Pariyatidhamma School, General Department, totaling 2,259 people [9]. The samples were selected by opening the sample size table of Krejcie, R. V. \& Morgan, D. W. [10]. The sample size of 335 sampleswere obtained. The sampling of each school district was carried out proportionally. The data were analyzed by descriptive statistics consisted of percentage, mean and standard deviation.

Step 2: Development of a participatory academic management model according to Buddhist principles of PhrapariyattidhammaSchool Department of General Education. It is a qualitative research by studying documents related to the principle of participatory academic management and Buddhist principles used to support and interviewed 14 key informants and analyzed the data through content analysis.

Step 3: Propose a participatory academic management model according to the Buddhist principles of Phrapariyattidhamma School, Department of General Education. It is a qualitative research by organizing focus group discussionwith experts to determine the suitability of the model by the experts who participated in focus group discussion, and 9 experts were selected according to purposive sampling with knowledge about participatory academic management from those who have knowledge of Buddhism or have knowledge of Phrapariyattidhamma School Department of General Education.

\section{Results}

1. Condition of Academic Management with participation of Phrapariyattidhamma School, the general education department as a whole has a high level of practice. When considering each of the 5 aspects, it was found that the level of practice was at a high level, all of which were the development of the quality assurance system within educational institutions, academic planning, educational supervision, teaching and learning managementand evaluation of learning outcomes in educational institutions, and research to improve the quality of education in educational institutions.

2. Development of a participatory academic management model according to Buddhist principles of Phrapariyattidhamma School Department of General Education. It is the implementation of 5 Buddhist principles, namely Sapphurisadham VII, SutthamIII, Four Noble Truth, BrahmawihanIV, and Iddhipada IV, to integrate with the 5 aspects of participatory academic management.

3. A participatory academic work management model according to Buddhist principles of Phrapariyattidhamma 
School, the general education department has 4 components: 1) Principle, 2) Objectives, 3) Administrative process is academic administration with participation and academic management with participation according to Buddhist principles. It consists of academic planning with Sappurisadham VII principles, teaching and learning management, and evaluation measurement with theSatdhamIII, research for the development of educational quality in educational institutions with the four noble truths, educational supervision and Brahmawihan IV principles of the system development. Quality assurance within educational institutions with the principle of Iddhipada IV, and, 4) Evaluation which is the evaluation by stakeholders such as monks, parents, community and comparative evaluation before and after the model is used as in Fig. 1.

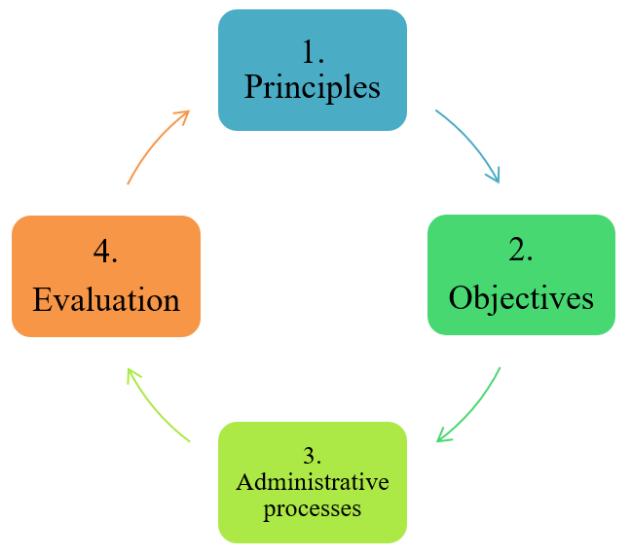

Fig. 1 A Model of participatory academic management model according to the Buddhist principles of

Phrapariyattidhamma School, General Education Division

There were results to propose a participatory academic management model according to the Buddhist principles of Phrapariyattidhamma School. The general education department found that it was appropriate and feasible to adopt a participatory academic management model according to the Buddhist principles of PhrapariyattidhammaSchool. Department

of General Education can be applied in educational institutions.

\section{Discussions}

This research found important points to be discussed as follows:

1. Condition of Academic Management with participation in Phrapariyattidhamma School the five general education departments are: 1) academic planning, 2) teaching and learning management and measurement, evaluation of learning outcomes in educational institutions, 3) research to improve educational quality in educational institutions, 4) Education supervision, and 5) development of quality assurance system within educational institutions. Overall, the operating conditions were at a high level.When considering the aspects from the areas with the highest performance ranking, it was found that the development of the quality assurance system within educational institutions. It has the first level of performance in academic planning and has the second highest level of practice in education supervision the level of practice was ranked the 3rd in the teaching and learning management and the evaluation of learning outcomes in educational institutions. Ranked fourth in the practice level for research to improve educational quality in educational institutions Has a performance level of rank 5, which is consistent with PriyawongAnutarot has proposed the idea that academic planning is very important and useful to educational institutions, helping to see problems and find a way to cure the fever from the beginning. Academic planning is essential to the performance of an academic institution, in advance of the future activities by studying information and facts to help workers be able to anticipate and prepare for solving problems and obstacles that arise. They can develop the school in the specified direction and can remain effective in society and administrators should have planning skills and be responsible for planning academic work at all levels by organizing meetings to discuss or listen to teachers' opinions in order to properly manage the planning, [11] and in accordance with Uthai Bunprasert mentioned the importance of academic work, academic work is the main work, the biggest work of the system, the work at the heart of the school and has a curriculum. This is the most important part of academic work to meet and support academic work for quality productivity [12].

2. Development of a participatory academic management model according to Buddhist principles of Phrapariyattidhamma School Department of General Education. It is a participatory academic management by integrating 5 Buddhist principles, namely, Sappurisatham 7, Sutta 3, Four Noble Truth, Brahmavihan 4, and Iddhipada IV with the 5 aspects of participatory academic management: 1) Academic planning, 2) Teaching and learning management and evaluation of learning management results, 3) Research to improve educational quality in educational institutions, 4) Educational supervision, 5) Development of the health insurance system within educational institutions which it is a research process resulting from document analysis related to academic management methods.Participation principles and Buddhist principles that are appropriate to integrate with academic administration including interviews with 14 key informants who are knowledgeable about this research until being able to develop into a form that are suitable as well. It is a model that goes through a qualitative research process such as document synthesis and interviewing key informants. The five principles are appropriate to apply to education especially the Four Noble Truths. This is consistent with the research of RungchatchadapornWehachat said that it is necessary to pay attention and develop one's potential to have knowledge and understanding and research capabilities to achieve policy success and lead to a more effective institutional mission. Research for the development of educational quality is based on the Four Noble Truths as a tool to promote the educational quality development process as well as the Four Noble Truthprinciple is a great truth consisting of 1) suffering problems that must be solved, 2) The cause of the aforementioned problems, 3) problem solving or goal, objective solution, and 4)method or means to solve problems. Executives can use these principles as a guide for their own development. Teacherdevelopment 
develops learners and improve the quality of educational institutions [13].

3. Development model for academic administration with participatory Buddhist principles of Phrapariyattidhamma School Department of General Education, it is a model development through document synthesis and interviews with 14 experts, then drafted a model for developing a participatory academic management model according to the Buddhist principles of Phra Pariyatidhamma School. The General Education Department consists of 4 components, component 1) principle component, 2) objectives component, 3) administrative process component, and 4) assessment. The model was then examined by a discussion meeting with a group of 9 experts which results to check the model. It was found that it was appropriate and feasible to develop a participatory academic management model. Buddhist principles of Phrapariyatidhamma School Department of General Education, this is related to ThawatchaiRattananu said that model development is a process of creating or developing a model that contains the study of related knowledge drafting the model and investigating the feasibility and feasibility of the model [14].

\section{Recommendations}

\section{A. Recommendations for practices}

Government Sector, Ministry of Education and school administrators the following actions should be taken:

1) The results of the research report should be improved in order to plan the research implementation for the development of education in educational institutions.

2) There should be a clear supervision plan through the supervisory committee appointed as well as head of the learning topic.

3) It should set up a policy and clear guidelines for academic administration that can be put into practice for concrete development.

B. 4)There should be a policy to encourage teachers to manage a variety of teaching and learning as well as a variety of evaluation results that are based on the real situation of the learners

\section{B. Recommendations for further research}

1. School administrators and special appreciation should be given to teachers with research results for outstanding educational development as well as organizing workshops for teachers to have knowledge and understanding in research for the development of educational quality.

2. School Administrators, there should be a document to educate teachers about teaching supervision. Materials, equipment, budget, morale and morale are supported for supervisors and supervisors. In addition, there should be a summary of the results of internal instructional supervision every semester.

3. School Administrators should be directed follow up on the ongoing and regular implementation of academic projects as planned.
4. School administrators, there should be a continuous meeting to clarify the results of the educational quality assurance to teachers, parents and the community. Data from the quality assessment results are used to improve and develop the quality assurance system within the school as well as providing facilities for the flexible and efficient development of the internal quality assurance system.

5. School Administrators Should support and promote the organization of workshops for teachers on the organization of teaching and learning activities with emphasis on critical thinking, synthetic thinking, critical thinking, creativity, thoughtfulness and have a vision tooling media technology in teaching and learning research to improve educational qualityassurance within educational institutions in order for teachers to apply the knowledge gained in organizing activities related to the quality development of educational institutions as well as preparing a manual for measuring and evaluating learning management in educational institutions.

\section{Conclusion}

A research paper on a participatory academic management model according to Buddhist principles of Phrapariyattidhamma School, Department of General Education, it is mixed methods research that combines both quantitative research and qualitative research. It is a participatory academic management by integrating 5 Buddhist principles, namely, SappurisadhamVII, SutdhamIII, Four Noble Truth, Brahmawihan IV, and Iddhipada IVwith the 5 aspects of participatory academic management: 1) Academic Planning, 2) Teaching and Learning Management and Evaluation of Learning Management Results, 3) Research for Educational Quality Development in Educational Institutions, 4) Educational Supervision, and 5) Development of an internal health insurance system. The model has 4 components: 1) Principle, 2) Objectives, 3) Administrative process, and 4) Evaluation. The summary of the knowledge from this research is that ADEBE MODEL that is an academic service that is the heart of the quality development of educational institutions. Developing teachers and learners use the principles of community and social participation and the introduction of 5 Buddhist principles into the integration of the academic administration will help promote the efficiency and sustainable effectiveness of the 5 academic administration by ADEBE MODEL as described below.

$\mathrm{A}=$ Administration is the academic administration in which the administrators manage the academic work according to the planned systematic plan. The principle of Buddhism is applied which is the Sapphurisadhamma VII, which is a principle that can greatly cover academic planning in which management must have a vision Policy to comply with government policy. The school condition was analyzed by SWOT. There were clear goals and policies in terms of quality and quantity. Administrators must have an assessment of the institution's job capability, including personnel, budget, materials, equipment and management system. Management must set a period of time for work in accordance with the plan. Therefore, management must have a systematic process of analysis and decision-making that 
defines a systematic approach and adjust it according to both internal and external situations or as an executive.

$\mathrm{D}=$ Development is the development of teaching and learning management and the measurement of learning performance that is the heart of academic administration. Executives must act effectively and efficiently in accordance with the government policy. And meet the expectations of teachers, learners, parents and the community, teaching and learning management, and learning performance measurement.It has applied Buddhism principles which are the 3 Dharma principles as a practice that will lead to success. Executives must always adhere to it on a regular basis, starting from themselves, being a person who adheres to ethics and is a good role model for education personnel, raising awareness for teachers and learners of their roles and responsibilities motivating teachers to act with an ideological commitment to teaching and learning and evaluating learners' learning outcomes. It also encourages teachers to develop diverse teaching skills and use modern teaching materials as well as judging the learning outcome of the learners according to the actual situation to develop educational institutions, personnel in teaching and learning management and evaluation of learning outcomes, resulting in students being of good quality.

$\mathrm{E}=$ Efficiency solution is an effective solution to problems through research to improve educational quality. There is a principle of Buddhism which is applied which is the Four Noble Truths, which the school administrators will manage to develop research and development of educational quality in that educational institution. Administrators must focus on the state of problems in researcher development or problems in promoting education personnel to acquire research skills at least set up problems or see problems as (suffering). In addition, administrators must also focus on studying the real causes of education that are the root causes of school problems that are connected to other problems in a comprehensive and straightforward manner (happiness). The root cause of the problem is known, one of the things management has to set clear goals in research area to meet the needs of most stakeholders or focus on solving problems in both the short and long term (nephrology) methods in research to improve the quality of education by searching for new methods to solve problems in a timely manner and to meet goals in order to benefit the administration of educational institutions.

$\mathrm{B}=$ Basis for success is a tool for success to achieve success in developing an educational quality assurance system within educational institutions is a very important workload in academic administration. It is an indication of the quality of the administrators, teachers, learners and educational institutes that they are very good. Therefore, the development of the quality assurance system in educational institutions with the principles of Buddhism that are applied which are the 4 virtues which can be regarded as the principles that lead to all success executives must have Chanta, Viriya, Chitta, and Vimangsa first.

Then, the administrators need to raise awareness of the educational institution personnel to be satisfied, and be willing and responsible for the development of an insurance system within the school encourage personnel to perform their assigned duties with determination, indomitable determination, management must regularly pay attention to, monitor, and advise personnel as well as having to study, analyze and consider insurance work in educational institutions to consider ways for continuous and sustainable development, and to lead the organization to the development of the quality assurance system within the school and the achievement of goals.

$\mathrm{E}=$ Equilibrium is the balance of educational supervision.It is very important to the quality of people and learners because educational supervision is a process to help teachers in all aspects whether it is teaching management. The performance of duties as assigned, help with media and teaching materials as well as the behavior or ethics of the teacher government. The principles of Buddhism that are applied are the four Brahma Vihara principles: mercy, compassion, empathy, and compassion must help and encourage the supervisor and the supervisor as well as management must rely on impartiality and use wisdom in considerationgood management needs to balance the way people treat personnel according to the four Brahmavihara IV principles. There must be a balance between compassion and empathy, and use blandness in being neutral do not allow personnel to violate the rules of the work, that is, the kindness of the personnel is too much to spoil the rules of work or to adhere to the rules of work strictly alone kind without kindness to personnel. All of them will lose balance and result in damage. This is something that good management must not do, and to develop a balance in educational supervision in educational institutions as in Fig. 2.

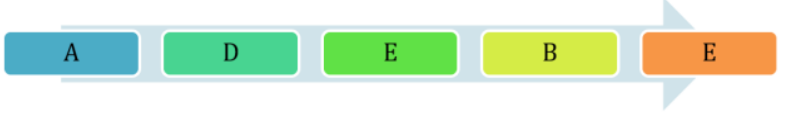

Fig.2 ADEBE MODEL

\section{References}

[1] Ministry of Education, 12-year basic education policy and management plan, Ministry of Education, Bangkok: Religion, 1999.

[2] Division of Buddhism Education, National Buddhism Office, Strategic Plan for Buddhist Studies General Education Department, Bangkok: Printing House of the National Buddhism Office, 2015.

[3] Office of Education Standards and Quality Assessment, Third Round External Quality Assessment Manual (2011-2015) Basic Education Level, Bangkok: Office for Educational Standards and Quality Assessment, 2011.

[4] P.Wonganutarot, Academic Administration, Bangkok: Sahamit Offset, 2003. 
[5] P.Sathon, Principles of administration, Study, Bangkok: Wattana Phanit, 1983.

[6] Evolved contract and male promise vivat, Buddhist management, Bangkok: Chulalongkorn University Press, 2007.

[7] C. Chanbanjong, Principles of Educational Administration, Bangkok: Chuan Pim, 1998

[8] National Buddhism Office, Educational Management Statistics Phrapariyattidhamma School Department of General Education, Bangkok: National Buddhism Office, 2015

[9] Krejcie, R. V. \& Morgan, D. W. Determining Sample Size for Research Activities, Educational and Psychological Measurement, 30(3), (1970): 607 - 610.

[10] P.Wonganutarot,

Academic Administration, Bangkok: Phimdee, 2001.

[11] U. Boonprasert, Applied Administration,Bangkok: Odeon Store, 1997.

[12] R.Wehachat, Academic Administration of Basic Education Institutions, 3rd edition, Songkhla: Nam Silpa Advertise, 2009.

[13] T.Rattanunyoo, "Development of the Model Management by using the school as a base in the school under the local administrative organization ", Doctor of Philosophy Thesis. Educational Administration Program, Graduate School: Siam University, 2008. 